\title{
Research on the Influence of Exchange Rate and Monetary Policy on RMB Internationalization
}

\author{
Han Liu \\ School of International Business, Southwestern University of Finance and Economics, Chengdu \\ 611130, China \\ hannlynn@163.com
}

\begin{abstract}
The change in exchange rate and monetary policy is closely related to RMB internationalization. Based on the background of RMB internationalization, this paper empirically analyzes the influence of RMB exchange rate and monetary policy on RMB internationalization by establishing VAR model. The empirical results show that the change of RMB exchange rate has a negative impact on RMB internationalization. Besides, the money supply also has a negative impact on the degree of RMB internationalization, but the impact is less than that of the exchange rate. Moreover, in the short term, interest rate has a negative impact on RMB internationalization, but it has a positive impact in the medium and long term. Therefore, relevant departments should continue to implement prudent monetary policies, speed up the reform of interest rate marketization, carry out the reform of RMB exchange rate prudently, maintain the stability of RMB exchange rate, and ensure the smooth progress of RMB internationalization.
\end{abstract}

Keywords: RMB internationalization, exchange rate, monetary policy.

\section{Introduction}

In 2001, China joined officially the World Trade Organization (WTO). Since then, China has been widely involved in global trade and has gradually grown into the world's second biggest economy. With the continuous improvement of comprehensive national power, RMB has begun to go global. In 2009, the pilot of RMB cross-border trade settlement reform opened officially the threshold of RMB cross-border circulation. As an important international settlement currency, RMB internationalization was launched officially. In 2015, "8.11 Exchange Rate Reform" further emphasized the principle of market supply and demand and the managed floating exchange rate. As the pace of exchange rate marketization accelerated, the two-way floating flexibility of the RMB exchange rate continued to increase. At the same time, investors' strong expectations on RMB devaluation have led to a slowdown in the progress of RMB internationalization. In 2016, the RMB was included in the Special Drawing Rights (SDR) currency basket. The number of countries with the RMB as the settlement currency increased significantly and the international status and recognition of the RMB was further enhanced. At present, China's exchange rate volatility has intensified. Capital outflow pressure has risen. Exchange rates and interest rates are undergoing market-oriented reforms. Monetary policy is undergoing a transition from quantity control to price regulation. Therefore, in this context, in order to better implement the RMB internationalization strategy and promote the grand strategy of "The Belt and Road", it is of great practical significance to discuss in detail the influence of exchange rate and monetary policy on the progress of RMB internationalization.

\section{Literature Review}

The relationship among exchange rate, RMB internationalization and monetary policy has always been the focus of attention from all walks of life and a large number of documents have been discussed. For example, Shen Yue et al. (2017) found that both money supply and interest rates have an impact on exchange rate fluctuations, but interest rates have a stronger effect. However, from a reverse perspective, the impact of exchange rate fluctuations on interest rates is greater than that on money supply. Therefore, in the choice of monetary policy, we should pay attention to the analysis of the sensitivity of exchange rate fluctuations and constantly strengthen the coordination between exchange 
rate policy and interest rate policy. The means of regulation should be based on price-based tools. Sun Shaoyan and Sun Wenxuan (2018) found that the two-way flexible fluctuation of exchange rate and the effect of monetary policy have positively promoted RMB internationalization. Besides, orderly guidance to adjust the flexibility of the RMB exchange rate can effectively hedge domestic excess capacity [2]. He Jinqi and Zhang Rui (2016) analyzed in detail the mechanism of RMB exchange rate and monetary policy on RMB internationalization. The change of RMB exchange rate will trigger the change of foreign investors' preference for RMB assets and the adjustment of overseas RMB asset stock, and thus affect RMB internationalization. The influence of monetary policy on RMB internationalization mainly plays a role through the exchange rate transmission mechanism of monetary policy [3]. Fang Shengqi and Zhang Xinmeng (2017) [4] believe that the increase in the degree of RMB internationalization will lead to an increase in the real effective exchange rate of RMB and the domestic money supply. The increase in the domestic money supply will lead to a bigger scale of RMB overseas deposits, while the increase in the real effective exchange rate will result in a smaller scale of RMB overseas deposits. Therefore, in the process of promoting RMB internationalization, active and prudent monetary policies and exchange rate policies should be implemented to better serve RMB internationalization. All in all, there is a close relationship among RMB internationalization, exchange rate and monetary policy. However, most of the existing researches are qualitative theoretical analysis and quantitative analysis is still rare. Based on this, this paper takes the degree of RMB internationalization as the research object, takes the relevant monthly data from 2008 to 2017 as samples and uses VAR model to analyze the dynamic influence of China's exchange rate and monetary policy on RMB internationalization under the new situation, in order to propose countermeasures and suggestions for RMB internationalization, exchange rate formation mechanisms and related reforms in the financial field.

\section{Empirical Research}

\subsection{Variable Selection and Data Source}

\subsubsection{RMB Internationalization Index}

For the measurement index of the degree of RMB internationalization, this paper selects the scale of the offshore RMB deposits in Hong Kong to measure this. Because the most important form of $\mathrm{RMB}$ in foreign countries is the offshore RMB deposit. In addition, since the offshore RMB market in Hong Kong is the largest financial transaction center for deposits and foreign RMB flows, also the world's most important hub for handling RMB cross-border trade settlement and payment and has developed into a very mature offshore RMB center with a certain scale, the Hong Kong RMB market is highly representative. Therefore, the scale of overseas RMB deposits is replaced by that of Hong Kong RMB offshore deposits. The data comes from Financial Data Monthly Report of the Hong Kong Monetary Authority.

\subsubsection{Monetary Policy Index}

In order to measure the trend of monetary policy, this paper selects the interest rate of the pricebased monetary policy proxy index and money supply of the quantitative monetary policy proxy index. The interest rate variable uses the SHIBOR data, which is the monthly data of the Shanghai Interbank Offered Rate. The data comes from the official website of SHIBOR. The money supply index uses the broad money supply M2, which comes from the official website of the National Bureau of Statistics.

\subsubsection{Exchange Rate Index}

After the exchange rate reform in 2005, the change of RMB exchange rate used RMB multilateral exchange rate index calculated in a basket of currencies as a reference. However, since the US dollar has an important position in the international reserve currency, the monthly central parity data of nominal exchange rate of the RMB against the US dollar has been adopted as the exchange rate index. The data comes from the official website of the State Administration of Foreign Exchange. 
In order to eliminate the influence of seasonal factors, the seasonal adjustment of the broad money supply (M2) is carried out. In order to alleviate heteroscedasticity, all variables are processed logarithmically in this paper. So far, there are four variables studied in this paper: broad money supply (LNM2_SA), Shanghai Interbank Offered Rate (LNSHIBOR), RMB exchange rate (LNERATE) and RMB internationalization degree (LNRMB).

\subsection{Unit Root Test}

The ADF unit root test results in Table 1 show that the monetary policy variable broad money supply (LNM2_SA) and the Shanghai Interbank Offered Rate (LNSHIBOR) are stable sequences at a 5\% significance level. The ADF test statistics of both the RMB exchange rate (LNERATE) and the RMB internationalization (LNRMB) variables are greater than the critical value at the 5\% significance level, so the null hypothesis cannot be rejected and both are non-stationary data. However, the ADF test statistics of their first-order difference sequence is less than the critical value at the 5\% significance level, so the null hypothesis can be rejected and $\triangle$ LnERATE and $\triangle$ LnRMB are considered to be the first-order integrated stationary sequences.

Table 1. Unit Root Test Results

\begin{tabular}{cccccc}
\hline Variable & Test Type & ADF Test Value & 5\% Critical Value & P Value & Conclusion \\
\hline LnM2_SA & $(\mathrm{c}, 0,1)$ & -4.4963 & -2.8859 & 0.0003 & Stable \\
LnSHIBOR & $(\mathrm{c}, 0,1)$ & -2.8929 & -2.8859 & 0.0492 & Stable \\
LnRMB & $(\mathrm{c}, 0,1)$ & -1.5774 & -2.8861 & 0.4909 & Non-stable \\
DLnRMB & $(\mathrm{c}, 0,1)$ & -4.5574 & -2.8861 & 0.0003 & Stable \\
LnERATE & $(\mathrm{c}, 0,1)$ & -1.9659 & -2.8861 & 0.3015 & Non-stable \\
DLnERATE & $(\mathrm{c}, 0,1)$ & -6.9294 & -2.8861 & 0.0000 & Stable \\
\hline
\end{tabular}

Note: In the test form (c, $\mathrm{t}, \mathrm{p}), \mathrm{c}$ refers to the constant term, $\mathrm{t}$ represents the trend term, and $\mathrm{p}$ is the lag order

\subsection{Cointegration Test}

As for cointegration test, this paper uses characteristic root trace test in Johansen cointegration test. The test results in Table 2 indicate that there is a cointegration relationship among the four variables and characteristic root trace test indicates that there are two cointegration vectors. According to the cointegration theory, for non-stationary time series, the VAR model can be directly established as long as there is a cointegration relationship among the variables.

Table 2. Characteristic Root Trace Test in Johansen Cointegration Test

\begin{tabular}{ccccc}
\hline $\begin{array}{c}\text { Hypothesized } \\
\text { No. of CE(s) }\end{array}$ & Eigenvalue & Trace Statistic & 0.05 Critical Value & Prob.** \\
\hline At most $1 *$ & 0.2093 & 39.0484 & 29.7971 & 0.0033 \\
At most 2 & 0.0708 & 11.5780 & 15.4947 & 0.1783 \\
At most 3 & 0.0253 & 2.9918 & 3.8415 & 0.0837 \\
\hline
\end{tabular}

Note: * indicates rejection of the null hypothesis at a significant level of 5\%; ** is the p value of Mackinnon-Haug-Michelis (1999)

\subsection{VAR Model Construction}

Through causality test, this paper uses the broad money supply (LNM2_SA), Shanghai Interbank Offered Rate (LNSHIBOR), RMB exchange rate (LNERATE) and RMB internationalization degree (LNRMB) to establish a VAR model. According to the lag length standard test, lag intervals for endogenous is 2, and all characteristic roots of the established VAR model are less than 1 (see Figure 1 ), indicating that the model satisfies the stability condition. 
Inverse Roots of AR Characteristic Polynomial

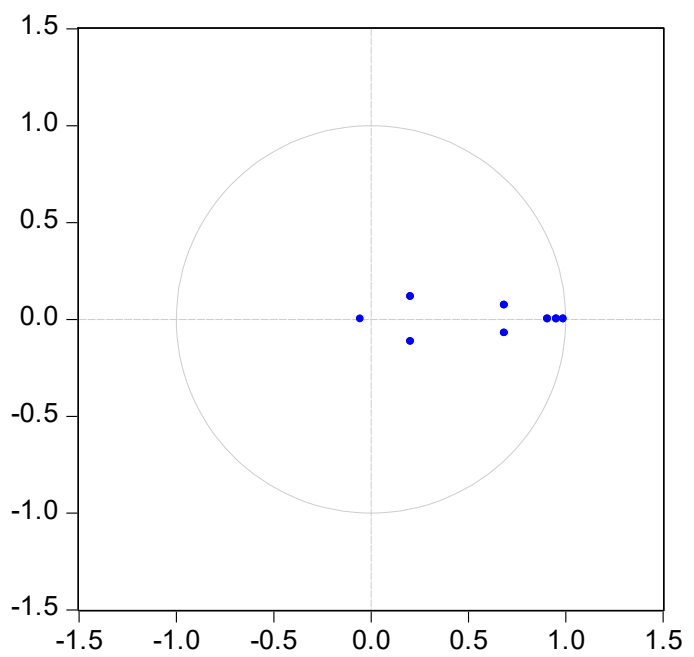

Figure 1. VAR model system stationarity test AR root

\subsection{Impulse Response Analysis}

The impulse response function method is to analyze the response of an endogenous variable to the impact caused by the error term, that is, the impact degree of the current value and the future value of the endogenous variable after applying a standard deviation to the random error term, which mainly describes the dynamic impact of the model on the system when it is subjected to an impact. Figures 2 to 4 show the impulse response of LNRMB's impact on monetary policy (LNM2_SA and LNSHIBOR) and RMB exchange rate (LNERATE) variables. Among them, the horizontal axis represents the number of lag periods of the impact. The vertical axis represents the amount of offshore RMB deposits. The blue line represents the degree of reflection of each impact variable on the offshore RMB and the red line represents deviation range of positive and negative twice the standard deviation.

In Figure 2, the LNRMB rapidly drops after a positive impact of a standard deviation of LNM2_SA, producing a negative reaction and increases over time. The main reason is that the increase in the money supply will lead to the expectation of RMB devaluation, followed by a reduction in holdings of the currency.

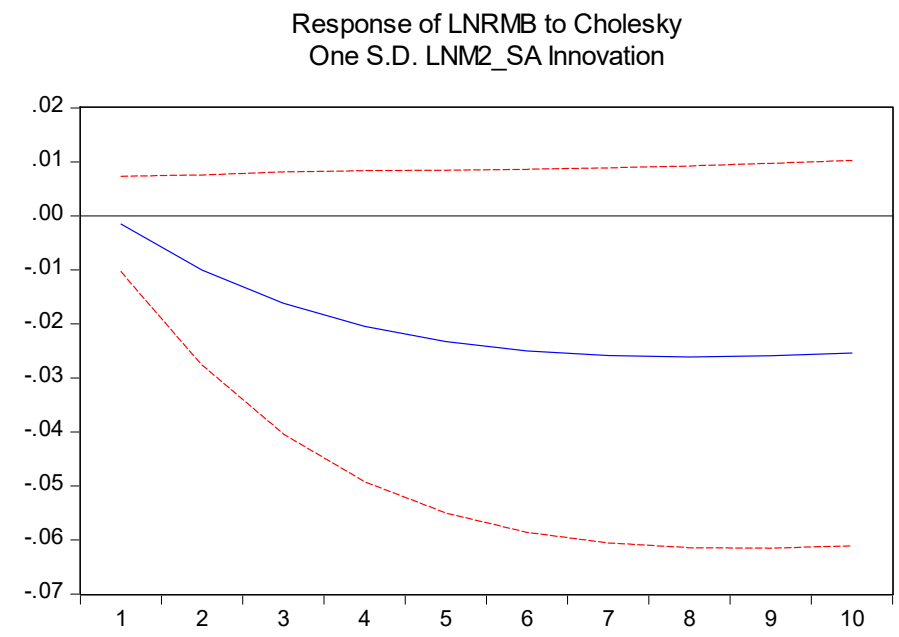

Figure 2. LNRMB impulse response to LNM2_SA

In Figure 3, after being positively impacted by a standard deviation of LNSHIBOR, the reaction of LNRMB is negative early but starts to change gradually to positive from the fourth period. This is because the rise in interest rates in the short term will lead to a decline in the supply of RMB in the money market. However, the rise in interest rates will lead to an increase in the demand for RMB in the medium and long term and an increase in the stock of RMB in the market. 


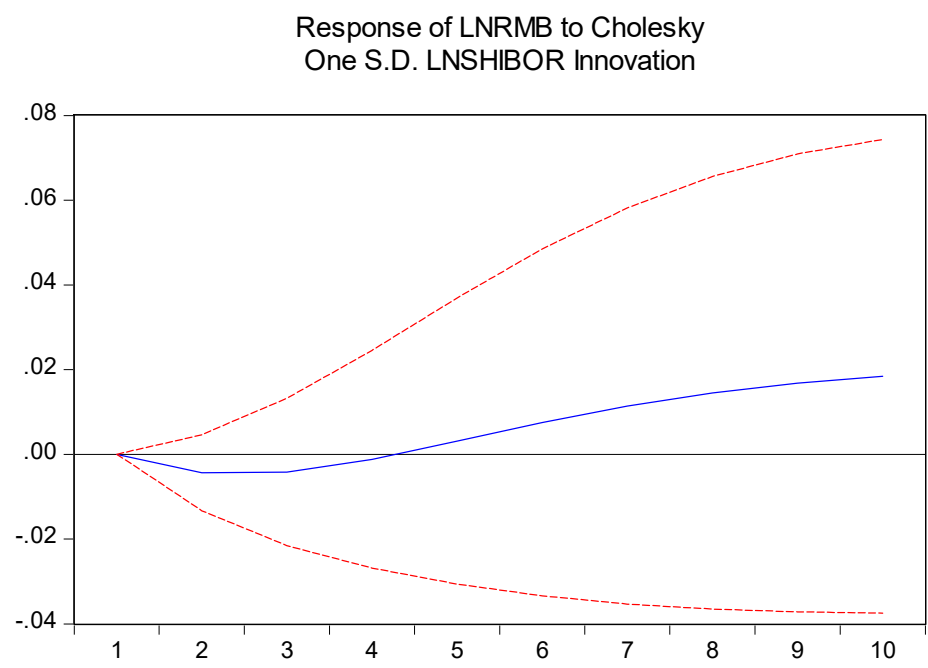

Figure 3. LNRMB impulse response to LNSHIBOR

In Figure 4, after the LNRMB is positively impacted by a standard deviation of LNERATE, the scale of offshore RMB deposits mainly shows a negative reaction. Therefore, the exchange rate changes have a greater negative impact on RMB internationalization.

Response of LNRMB to Cholesky

One S.D. LNERATE Innovation

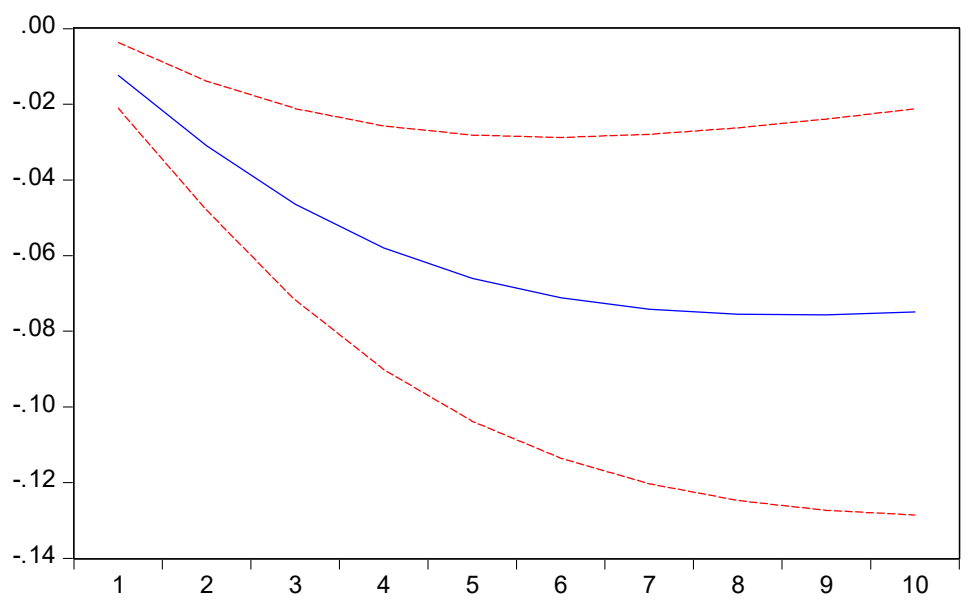

Figure 4. LNRMB impulse response to LNERATE

\subsection{Variance Decomposition}

The introduction of variance decomposition analysis is helpful to analyze the contribution of each structural impact to the change of endogenous variables and can further evaluate the importance of different structural impacts. Table 3 shows the results of LNRMB variance decomposition for ten periods.

Table 3. Variance Decomposition of RMB internationalization

\begin{tabular}{cccccc}
\hline Period & S.E. & LNM2_SA & LNERATE & LNRMB & LNSHIBOR \\
\hline 1 & 0.0067 & 0.0989 & 6.6301 & 93.2710 & 0.0000 \\
2 & 0.0094 & 1.1313 & 12.1510 & 86.5101 & 0.2076 \\
3 & 0.0117 & 1.7910 & 16.0696 & 81.9601 & 0.1793 \\
4 & 0.0138 & 2.2498 & 19.0523 & 78.5894 & 0.1086 \\
5 & 0.0157 & 2.5817 & 21.3991 & 75.9265 & 0.0927 \\
6 & 0.0174 & 2.8269 & 23.2743 & 73.7476 & 0.1512 \\
7 & 0.0191 & 3.0098 & 24.7838 & 71.9369 & 0.2695 \\
8 & 0.0206 & 3.1466 & 26.0043 & 70.4243 & 0.4248 \\
9 & 0.0221 & 3.2490 & 26.9949 & 69.1596 & 0.5966 \\
10 & 0.0235 & 3.3250 & 27.8023 & 68.1028 & 0.7698 \\
\hline
\end{tabular}


According to Table 3, the offshore RMB deposit size (LNRMB) fluctuates between $68.10 \%$ and 93.27\%. Among the external impact factors, the impact of the RMB exchange rate (LNERATE) fluctuates from $6.63 \%$ to $27.80 \%$. The exchange rate has the highest ability to explain the scale of offshore RMB deposits, followed by the money supply (LNM2_SA), reaching 3.33\% at the highest. Interest rates have the lowest explanatory ability for offshore RMB deposits, with a maximum of $0.77 \%$. Therefore, the degree of RMB internationalization is most affected by the size of offshore RMB deposits. In addition, the exchange rate also has an important impact on the degree of RMB internationalization. This is because the exchange rate will affect the scale of offshore RMB deposits. The currency circulation M2 and the interest rate LNSHIBOR also have a certain impact on the degree of RMB internationalization, but the degree of influence is small.

\section{Conclusions and Policy Recommendations}

Based on the economic background of RMB internationalization, two-way exchange rate fluctuation and interest rate marketization reform, this paper studies the short-term dynamic influence of RMB exchange rate and monetary policy on RMB internationalization progress by constructing VAR model. The empirical results show that the exchange rate, interest rate and money supply will have certain impact on the scale of offshore RMB deposits. The RMB exchange rate and money supply have a significant negative impact on RMB internationalization. Interest rates have a negative impact on RMB internationalization in the short term, but positive in the medium and long term. The exchange rate has a greater impact on RMB internationalization and the impact of interest rates and money supply is relatively weak. Therefore, although the development progress of RMB internationalization mainly relies on market forces, appropriate policy promotion is indeed beneficial to RMB internationalization. Based on the above analysis, this paper mainly has the following enlightenment. First, we should continue to implement a prudent monetary policy to prevent the excessive money supply from causing a decline in expected interest rates of RMB and a sharp fall in the exchange rate, which will have a negative impact on RMB internationalization. At the same time, we should accelerate the transformation of the monetary policy framework and make full use of interest rate price instruments. Second, we should maintain a flexible exchange rate system arrangement, avoid large fluctuations in the RMB exchange rate, improve the stability of the RMB in the international market, and actively cooperate with the progress of RMB internationalization. Third, we should make full use of market-oriented means to regulate interest rates and optimize the allocation of financial resources through interest rate and exchange rate advantage, effectively improving the efficiency of resource allocation. Finally, it is worth mentioning that RMB internationalization is in line with the fundamental interests of China's economic development, the inevitable result of China's reform, opening up, and the general trend of the development progress. Under the current world economic situation, RMB internationalization will certainly encounter twists and turns, but the future development situation is good and the bright future can be expected.

\section{References}

[1]. Shen Yue, Wang Fei, Guo Peili. Analysis of the Interaction Effect between Exchange Rate Fluctuation and Monetary Policy Regulation - - Based on the Perspective of RMB Internationalization[J]. Economic Survey, 2017(4): 55-61.

[2]. Sun Shaoyan, Sun Wenxuan. The Impact of Exchange Rate Fluctuation and Monetary Policy on RMB Internationalization- - An Empirical Analysis Based on VECM Model[J]. Economic Issues, 2018 (2): 43-48.

[3]. He Jinqi, Zhang Rui. Research on the Interaction among RMB Internationalization, Exchange Rate Fluctuation and Monetary Policy [J]. Audit and Economic Research, 2016, 31(3): 120-129. 
[4]. Fang Shengqi, Zhang Xinmeng. RMB Internationalization, Exchange Rate Fluctuation and Domestic Money Supply- - An Empirical Study Based on State Space Model and SVAR Model[J]. Journal of Nanjing Aerospace University (Social Science Edition), 2017, 19(2): 53-58. 